\title{
INFLUENCIAS DEL TEATRO EUROPEO EN EL PRIMER TEATRO INDEPENDIENTE DE BUENOS AIRES
}

\author{
INFLUENCES OF THE EUROPEAN THEATER IN THE FIRST \\ INDEPENDENT THEATER OF BUENOS AIRES
}

\author{
María Fukelman \\ Universidad de Buenos Aires. Buenos Aires, Argentina. \\ mariafukelman@gmail.com
}

\begin{abstract}
Resumen: El Teatro del Pueblo fue creado en Buenos Aires el 30 de noviembre de 1930 por iniciativa del escritor y periodista Leónidas Barletta. Este espacio fue tomado por la crítica especializada como el primer teatro independiente de Buenos Aires. A su vez, varios de los postulados que se llevaron a cabo por el Teatro del Pueblo se habían estado ejecutando desde hacía bastante tiempo en algunas ciudades europeas. Distintos teóricos y protagonistas de los comienzos del teatro independiente sostuvieron que noticias referidas al tema llegaban a Buenos Aires y se vinculaban con la nueva práctica teatral que estaba surgiendo aquí. El propósito de este trabajo es, entonces, dar cuenta de las diferentes corrientes del teatro europeo que fueron consideradas antecedentes del teatro independiente porteño, clasificarlas y observar en qué puntos pueden ser tomadas como influencias para el Teatro del Pueblo.
\end{abstract}

Palabras clave: Leónidas Barletta, Teatro del Pueblo, antecedentes, Europa, Vanguardia.

\begin{abstract}
The People's Theater was created in Buenos Aires on November 30, 1930 at the initiative of writer and journalist Leónidas Barletta. This place was taken by the specialist criticism as the first independent theater in Buenos Aires. In turn, many of the assumptions that were performed by the Teatro del Pueblo had been running for quite some time in some European cities. Different theorists and protagonists of the early independent theater argued that news relating to the subject came to Buenos Aires and these were linked with the new theatrical practice that was emerging here. Then, the purpose of this paper is to account for the different currents of European theater that were considered part of the history of independent theater in Buenos Aires, to classify them and to observe what points can be taken as influences for the Teatro del Pueblo.
\end{abstract}

Keywords: Leónidas Barletta, People's Theatre, background, Europe, Avant-garde.

Recibido: 27.07.2016. Aceptado: 20.12.2016. 
$\mathrm{E}$ L Teatro del Pueblo fue creado en Buenos Aires el 30 de noviembre de 1930 por iniciativa del escritor y periodista Leónidas Barletta. Este espacio fue considerado por la crítica especializada como el primer teatro independiente de Buenos Aires. A pesar de que ya había habido otros intentos por conformar un teatro libre en la ciudad, el Teatro del Pueblo fue el primero que alcanzó continuidad en el tiempo.

Varios de los postulados que se llevaron a cabo por el Teatro del Pueblo se habían estado ejecutando desde hacía bastante tiempo en algunas ciudades europeas. Una de las preguntas que nos podemos hacer es si Leónidas Barletta conocía lo que estaba sucediendo en Europa. Sostenemos que sí, ya que en varias publicaciones de la época, como Claridad. Tribuna del pensamiento izquierdista, Anuario Teatral o Martín Fierro, se difundían artículos sobre el teatro de vanguardia europeo. Distintos teóricos y protagonistas de los comienzos del teatro independiente en Buenos Aires dieron cuenta de esto (cfr. Octavio Palazzolo en Marial, 1955; Marial, 1955; Ordaz, 1957) y vincularon esas noticias con la nueva práctica teatral que estaba surgiendo aquí (cfr. Vicente Martínez Cuitiño en Ordaz, 1957; Ordaz, 1992). Además, Barletta era un ferviente admirador de Romain Rolland, quien en 1903 publicó su libro El Teatro del Pueblo. Ensayo de estética de un Teatro Nuevo. Este texto tuvo una segunda edición en 1913 y se tradujo al castellano tres años antes de la fundación del Teatro del Pueblo, aunque también podemos suponer que Barletta ya lo había leído en su idioma original (cfr. Larra, 1978). El hecho de que su teatro se llame igual que el libro da la pauta de que Barletta había leído el material y suscribía a él. Sin embargo, la teoría propuesta por Rolland no fue tomada de manera lineal por el teatrista argentino. En este sentido, sostenemos que Barletta se sirvió de distintas vertientes para sentar las bases del teatro independiente en Buenos Aires, práctica que trajo aparejadas sus propias particularidades.

Tomando como marco la teoría que propone el Teatro Comparado (Dubatti, 2012a), entendemos que la relación interterritorial entre ambos continentes se da a partir de un vínculo genético. En esta territorialidad diacrónica la irradiación es producida a través de las diferentes publicaciones. Empero, no se trasladaron los rasgos europeos a Buenos Aires sin modificaciones sino que se tomaron determinados conceptos de distintos grupos y figuras para dar forma a una modalidad propia y singular. Según los aportes antes aludidos, los grupos y figuras que, a priori, podríamos 
considerar antecedentes del teatro independiente son, como ya hemos mencionado (Fukelman, 2015):

-André Antoine, creador del Théâtre-Libre (Teatro Libre), fundado en París, en 1887.

-Otto Brahm, creador y supervisor de Die Freie Bühne (La Escena Libre), fundado en Berlín en 1889 por 10 escritores y críticos.

-Jacob T. Grein, creador de The Independent Theatre Society (La Sociedad de Teatro Independiente), fundada en Londres en 1891.

-Lugné-Poé, quien se hizo cargo en 1893 de la dirección del Théâtre d'Art (Teatro de Arte), fundado en 1891 en París por Paul Fort. Durante su gestión, el teatro pasó a llamarse L'Euvre (La Obra).

-Edward Gordon Craig, quien comenzó a trabajar como actor pero desde 1897 se inclinó al arte escenográfico.

-Konstantín Stanislavski y Vladimir Nemirovich-Danchenko, fundadores del Teatro de Arte de Moscú en 1898.

-Romain Rolland, quien publicó en París su libro Teatro del Pueblo. Ensayo de Estética de un Teatro Nuevo en el año 1903.

-Jacques Copeau, fundador en 1913 de su teatro Vieux-Colombier (El Viejo Palomar).

-Max Reinhardt, primer director de Die Volksbühne (El Teatro del Pueblo), en Berlín, entre 1915 y 1918.

-Erwin Piscator, creador, junto a Hans José Rehfisch, del Teatro Proletario en Berlín en 1922; y luego, en la década del '30, director de Die Volksbühne.

-Anton Bragaglia, creador del Teatro Sperimentale degli Indipendenti (Teatro Experimental de los Independientes) en 1922.

-El Mirlo Blanco, teatro de cámara creado, en 1926, en el domicilio de Ricardo Baroja y su esposa, Carmen Monné, en Madrid.

-La Compañía del Cántaro Roto, de Ramón Valle-Inclán y Cipriano de Rivas Cherif, fundado en Madrid en 1926.

-El Caracol, de Cipriano de Rivas Cherif, fundado en 1927.

Son muchos los grupos y figuras que integran la lista y que, de alguna manera u otra, podemos tomar como antecedentes del teatro independiente porteño. No todos son iguales y se conectan entre ellos de diferentes 
maneras. A modo de síntesis, pensamos que los conceptos propagados por ellos y que luego fueron tomados por el Teatro del Pueblo son "teatro libre / independiente", "teatro de arte" y "teatro popular". Estos elementos son los que conformarían la macropoética ${ }^{1}$ de los antecedentes europeos del teatro independiente.

\section{Teatro libre / independiente}

El puntapié inicial del teatro libre o independiente se dio en París, con la fundación del Théâtre-Libre (Teatro Libre) en 1887, y luego se fue propagando dentro del territorio y también a países vecinos. En pocos años, eran tres las capitales de Europa que contaban con su teatro libre: en 1889 surgió en Berlín, Die Freie Bühne (La Escena Libre); y en 1891, The Independent Theatre Society (La Sociedad de Teatro Independiente), en Londres.

El concepto de teatro libre o independiente que surgió en Europa y que, más adelante, Barletta y otros escritores propusieron para la escena porteña, tiene que ver con un nuevo modo de pararse en el campo teatral, con una postura política tomada por los artistas.

Estas nuevas prácticas teatrales se distanciaban del teatro producido comercialmente para entretener y del que producía el Estado. En este sentido, rechazaban ciertos recursos actorales, como el estilo interpretativo, la afectación, la declamación y la exageración; y la figura de los cómicos se encontraba en las antípodas de lo que el nuevo teatro quería proponer. Además, se oponían a los decorados prototípicos (en general, "cartón pintado") que se utilizaban y promovían la moderación de los actores en escena. La práctica teatral era tomada con seriedad, y no como un juego de aficionados.

El Théâtre-Libre (Teatro Libre), de André Antoine, surgió como un laboratorio experimental para los iniciados, y como un teatro de provoca-

\footnotetext{
${ }^{1}$ Llamamos macropoética al resultado "de los rasgos comunes y las diferencias de un conjunto de entes poéticos seleccionados (de un autor, de una época, de una formación, de contextos cercanos o distantes, etc.). Implica trabajar sobre realizaciones teatrales concretas, sobre individuos teatrales, por lo tanto requiere el conocimiento previo de las micropoéticas. En el trayecto inductivo, las macropoéticas marcan un paso más hacia la abstracción de los modelos lógicos: son generalmente el camino indispensable para la conformación de las archipoéticas" (Dubatti, 2012a: 131).
} 
ción, ya que se oponía al teatro oficial de la Comedia Francesa y a las escenas comerciales del Boulevard. Estableció un modelo de teatro realista y se especializó en dramas de tesis. También presentó un gran número de obras inéditas o escritas por dramaturgos jóvenes, e introdujo en Francia obras de autores extranjeros.

Die Freie Bühne (La Escena Libre) fue fundada por 10 escritores y críticos, y supervisada por el director y guionista Otto Brahm. Su propósito fue poner en escena nuevas obras naturalistas. Si bien la Freie Bühne fue un éxito que duró solo tres temporadas -en gran parte porque, para ese entonces, el teatro comercial de Berlín también estaba abocado al nuevo movimiento teatral del naturalismo-, inspiró la creación de otros teatros y grupos de aficionados de todo Berlín, Munich y Viena.

The Independent Theatre Society existió en Londres entre 1891 y 1897 , fue fundada por el crítico de teatro holandés Jacob Grein con la intención de poner en escena obras de teatro con un valor estético en lugar de comercial. La Sociedad de Teatro Independiente se inspiró en sus precursores continentales, el Théâtre-Libre y Die Freie Bühne. Al igual que otros teatros del estilo, la afiliación era por suscripción, es decir, que las actuaciones no eran "públicas". De esta manera evitaron la censura en más de una oportunidad. En 1892, Grein se acercó al entonces joven escritor irlandés George Bernard Shaw para pedirle una obra de teatro. Shaw estrenó Casa de viudas en la Sociedad de Teatro Independiente y tres años más tarde escribió:

La Sociedad de Teatro Independiente es una institución excelente, simplemente porque es independiente. Los que la menosprecian preguntan de qué es independiente... Es, por supuesto, independiente del éxito comercial... Si el señor Grein no hubiese puesto a los críticos dramáticos de Londres frente a Espectros y El pato salvaje, con un pequeño pero curioso e influyente cuerpo de entusiastas detrás de ellos, seríamos mucho menos avanzados de lo que hoy $\operatorname{somos}^{2}$ (1895: 126).

Con una postura política todavía más enfatizada, Erwin Piscator creó, junto a Hans José Rehfisch, el Teatro Proletario en Berlín. Entre 1922 y 1923, la agrupación produjo obras de Máximo Gorki, Romain Rolland y

\footnotetext{
${ }^{2}$ La traducción es nuestra.
} 
León Tolstoi. Luego, entre 1924 y 1927, Piscator fue director del ya mencionado Die Freie Bühne y allí produjo obras con contenido social y político, con el objetivo de difundir y clarificar las ideas políticas izquierdistas. Piscator defendió el teatro didáctico que enseña y explica a sus espectadores. Su intención siempre fue la de utilizar el teatro con un fin social:

Desde el comienzo, desde la primera frase, persigo la comprensión, el análisis, la claridad, la simplicidad y, si es necesario para que se comprenda, la simplificación. La expresión "teatro didáctico" tiene una mala reputación, al igual que el teatro de propaganda o teatro de tendencia (...). Algunos críticos se complacen en llamar "panfletario" a este teatro épico. Y bien, ¿qué tiene de malo un panfleto? Si se emplea para un buen fin logra a veces ser muy útil (Piscator, 1979: 47).

Si bien todos estos grupos tuvieron un cariz distinto, se pueden considerar dentro de la misma genealogía por su actitud de "recortarse" de un contexto y promover un arte con contenido social.

\section{Teatro de arte}

La segunda línea de los teatros de vanguardia europeos que luego se retomó en Buenos Aires tiene que ver con la pretensión de realizar un teatro de arte. El propósito de llevar a cabo un arte bello fue común a todos los exponentes de este nuevo teatro. La mayoría también sostuvo el fin de experimentar, aunque no todos se autodenominaron "vanguardia".

En 1891, cuatro años más tarde de la creación del Teatro Libre, también en París, Paul Fort creó el Théâtre d'Art. René Lalou da cuenta de que se opuso a la estética realista que había propuesto Antoine:

Fue para protestar contra ese imperialismo que Paul Fort (...) fundó el Théâtre d'Art. Lo colocaba bajo el patrocinio de Mallarmé, de Verlaine, de Verhaeren. Solicitaba el concurso de jóvenes pintores, tales como Bonnard, K. X. Roussel y Vuillard. (...) Nadie, ni siquiera el director, habría podido decir exactamente cómo la empresa cubría sus gastos. Pero duraba, demostrando que un teatro poético podría oponerse, en París, tanto al teatro de entretenimiento como al teatro realista (1962: 15-16). 
Lugné-Poe, que había debutado como actor y asistente en el teatro de Antoine, en 1891 se unió al Théâtre d'Art como actor y colaborador. A partir de 1893 se hizo cargo del teatro, le cambió el nombre a L'Euvre (La Obra) y declaró que la verdadera razón de ser de este espacio era "constituir, junto al teatro contemporáneo de tesis sociológicas o morales, de centro verosímil y fijo, un teatro semimágico que anime el poema, un teatro de la fantasía y el sueño" (Lalou, 1962: 16).

En Rusia, por otra parte, se creó el Teatro de Arte de Moscú en 1898. Sus fundadores fueron Vladímir Ivánovich Nemiróvich-Dánchenko y Konstantin Stanislavski, quienes querían crear un nuevo tipo de teatro, dedicado a los altos estándares de actuación y producción. Además, buscaban que el teatro fuera popular, con precios accesibles. Su intención era que el teatro fuese también una herramienta de educación. Años después, Stanislavski definió los presupuestos teóricos de la nueva compañía de la siguiente manera: "Nuestro programa era revolucionario; nos rebelamos contra el antiguo estilo interpretativo, la afectación y el falso patetismo, contra la declamación y la exageración bohemia, contra el erróneo convencionalismo en la puesta en escena y en los decorados, contra el star-system, que arruina el conjunto, y la mediocridad del repertorio" (en Paul, 2013: 3). Ellos tenían la pretensión de suprimir la preponderancia del primer actor y la primera actriz por sobre el resto de la compañía, intentando un criterio que atribuyera a la representación el interés del conjunto.

Enmarcamos a este teatro dentro de la línea de la búsqueda de un arte bello por algunas cuestiones ya mencionadas y por el título de su espacio. No obstante, entendemos que la división no está tan clara y que también tiene muchas conexiones con el teatro político que comenzara el Teatro Libre. Según Cipriano de Rivas Cherif:

El arte de Antoine y sus colaboraciones correspondió en el teatro al naturalismo realista de la novela triunfante años antes con Zola y sus congéneres. Ese realismo naturalista, minuciosamente detallado en la composición escénica, constituyó el precio del Teatro Artístico de Moscú. Anton Chejov es el dramaturgo característico de aquella primera época. El éxito, después, del Asilo de noche, de Máximo Gorki, imprime al Teatro Artístico un sello más particular aún. Teatro Gorki vino a llamarse cuando la Revolución, convirtiéndolo en academia dramática 
muy principal del Estado soviético, manteniendo a Stanislavsky ${ }^{3}$ como director de su fundación, atribuyó a sus representaciones la función pública, conferida a todos los teatros de la URSS (2013: 36).

Asimismo, en 1911 se había instalado en Florencia, renegando de su profesión de actor en Inglaterra, Gordon Craig, quien comenzó en Italia una campaña en pro del renacimiento del teatro en relación con las artes plásticas. Así, instituyó una Escuela Teatral en la Arena Goldoni, edificio desafectado de un viejo teatro al aire libre y publicó una esplendorosa revista en lengua inglesa, con dibujos y grabados sin fotografías, titulada The Mask (La Máscara). Para De Rivas Cherif:

\begin{abstract}
Propugnó, desde luego, la reivindicación del estilo teatral en sus símbolos esenciales, abominó del realismo y de la imitación aparente de la vida cotidiana, vinculó a la gracia típica de las máscaras tradicionales de la commedia dell'arte y a la improvisación del diálogo sobre pautas o argumentos ajustados al ritmo de un movimiento traducido en signos fijos por la pantomima clásica, la renovación del gusto moderno de la escena, decadente en la grisalla, la lentitud y el aburrimiento del teatro sin fantasía poética. Llegó a proclamar la ventaja de la marioneta sobre el intérprete vivo, con ideas propias y sin capacidad suficiente de abstracción. Su influencia difusa fue muy grande; pero no constituyó verdadera escuela ni, sobre todo, fundó un teatro ni compañía alguna. Influyó, más bien, en la decoración teatral (2013: 37).
\end{abstract}

En 1913, el francés Jacques Copeau abrió su teatro Vieux-Colombier (El viejo palomar). $\mathrm{Su}$ inicio fue la consecuencia natural de los ataques que Copeau lanzaba, en sus crónicas de la revista de la $N R F$ (Nouvelle Revue Française), contra los especuladores y los bufones de su tiempo. Al respecto, Copeau expresó en 1920: “Teníamos amor por el teatro. Lo veíamos abandonado a las especulaciones de los explotadores, y deseábamos que fuera devuelto al quehacer de los creadores" (en Lalou, 1962: 60). José María Monner Sanz ubica a Copeau en la línea del Théâtre d'Art y de, entre otros, Piscator, Stanislavski y Nemiróvich-Dantchenko; aunque avanzando en su propio camino.

\footnotetext{
${ }^{3}$ Escrito así, en el original.
} 
Después de un tiempo en Nueva York, el 7 de abril de 1919, la compañía del teatro Vieux-Colombier dejaba la ciudad. En noviembre nacía la asociación de los amigos y fundadores del Vieux-Colombier en París. Parecía que el éxito material se había alcanzado, pero en 1924, Copeau decidió renunciar. Lalou explica: “...sus fuerzas se debilitaron, no solo por la pesada experiencia de Nueva York y por los cinco años de dirección en París: más penosa aún fue para él la hostilidad que provocó en su propia compañía su propósito de formar e instruir un equipo de jóvenes, o como él decía, de 'formar un coro', ya que 'el coro es la célula madre de toda poesía dramática”" (1962: 68). El teatro Vieux-Colombier realizó otro gran aporte al teatro francés: entre otras novedades, organizó una escuela de arte dramático para enseñar a los actores y proyectó la escenografía en función de las particularidades de cada obra.

Contemporáneamente a Copeau, surgía en Alemania la figura de Max Reinhardt. De Rivas Cherif sintetiza:

Casi al mismo tiempo, surgían en Alemania y en Francia dos grandes renovadores de la escena moderna, Max Reinhardt y Jacques Copeau, fundador este último del Teatro del Vieux Colombier (del Palomar Viejo, por la calle del Barrio Latino de París en que está). Probablemente Copeau es quien mejor ha realizado, corrigiéndolas a la medida francesa, las teorías de Gordon Craig. Reinhardt, por caminos más espectaculares, con más tramoya y maquinaria, con más elementos materiales, cumple en el mundo teatral germánico el designio de los nuevos artistas del teatro. Su época, netamente definida en los años de una guerra a la otra (1914-1936), es la del predominio del director de escena, no ya sobre el actor, sobre el propio autor dramático (2013: 37).

Ya en 1922, Anton Bragaglia fundó en Italia el Teatro Sperimentale degli Indipendenti (Teatro Experimental de los Independientes), y un breve tiempo después llegaron las primeras experiencias españolas. En 1926 nació El Mirlo Blanco, teatro de cámara creado en el domicilio de Carmen Monné y su esposo, Ricardo Baroja, en Madrid. Desde 1923 se reunían las noches de los sábados en la casa del matrimonio Baroja un grupo de escritores, entre los que se encontraban De Rivas Cherif, Manuel Azaña, ValleInclán, los hermanos de Ricardo, Pío y Carmen Baroja, entre otros. En una de las tertulias sabatinas se decidió crear un teatro para representar obras 
de los propios asistentes que no llegaban a los teatros comerciales madrileños. Se le dio el nombre de El Mirlo Blanco en atención a su rareza dentro de la escena española y como un guiño irónico a El pájaro azul de Maeterlinck y a otras aves del imaginario simbolista.

Ramón María del Valle-Inclán, habitué de la casa de los Baroja, también fundó su propio grupo. A fines de 1926 dio vida, junto a Cipriano de Rivas Cherif a la Compañía del Cántaro Roto. Y en 1927, De Rivas Cherif fundó otro conjunto: El Caracol, anagrama de Compañía Anónima Renovadora (del) Arte Cómica Organizada Libremente. Esta compañía realizó giras por Buenos Aires y Montevideo.

Enrique de Rivas advierte entre los predecesores del teatro de De Rivas Cherif a Stanislavski y Nemirovich-Danchenko.

Tanto Bragaglia en Italia como De Rivas Cherif en España se pueden ubicar en la genealogía del Teatro de Arte de Fort, que luego continuó Lugné-Poe con La Obra, ya que no acordaban con el naturalismo. Monner Sanz sostuvo que, para estos directores, cualquier escenografía realista estaba "en pugna con la índole del teatro actual” (1958: 29). No obstante, De Rivas Cherif tampoco creía en una visión puramente estética del arte:

Decir teatro artístico parece una redundancia. Lo es. Pero expresiva de una determinada condición o cualidad. Se dice, desde hace ya casi medio siglo, teatros artísticos a cierta categoría de compañías, empresas o intentos cuya actividad especial, que de ese título se galardona, supone la reivindicación del arte, perdido en el comercio, rutinario en fuerza de usual, del teatro vulgar y corriente.

La estimación puramente estética de las cosas todas en general, la consiguiente atribución al Arte con mayúscula de esa virtud creadora de Belleza y enjuiciadora del Gusto, es moderna. En punto al teatro en particular, modernísima. La Antigüedad no produjo ninguna obra artística que tuviera un fin en sí misma. La fórmula del 'arte por el arte' es una limitación más de nuestro tiempo (2013: 34).

El Teatro Experimental de los Independientes, El Mirlo Blanco, la Compañía del Cántaro Roto y El Caracol eran exponentes del teatro experimental de vanguardia. Empero, recibían apoyo económico del Estado (cfr. Vicente Martínez Cuitiño en Ordaz, 1957). 


\section{Teatro popular}

Los propulsores de este concepto ubicaron al pueblo en el centro de sus destinatarios y todas sus decisiones viraban en torno a un teatro que fuera para todos. Ofrecieron, entre otras cuestiones, las entradas a un costo bajo e igual para todo el público. Advirtieron la necesidad de que el escenario fuera grande para que pudieran entrar las masas y de que en la sala se viera bien desde todos lados.

El principal representante del teatro popular fue Romain Rolland, quien presentó la doctrina de este tipo de teatro en su libro El Teatro del Pueblo. Ensayo de Estética de un Teatro Nuevo. No obstante, el autor ubica al Volkstheater (Teatro del Pueblo) de Viena, que estrenó en 1889 La mancha en el honor de Anzengruber, como el primer teatro popular del mundo. En esta misma línea, suma al Schiller Theater, que abrió sus puertas en Berlín en 1894, dirigido por M. Loewenfeld. Este espacio contó con 6.000 abonados al año de su apertura, y la compañía estuvo compuesta por una treintena de artistas, que interpretaban un repertorio tanto clásico como moderno. Rolland sostiene que a partir de la prosperidad de esta situación, se abrieron en Berlín otros dos teatros Schiller.

Dentro de Francia, Rolland considera fundador del Teatro del Pueblo a Mauricio Pottecher, quien el 22 de septiembre de 1892, en el centenario de la fundación de la República, representó -con gran éxito- El médico a pesar suyo, en su pequeña villa de los Vosgos y, tres años más tarde, inauguró el Teatro del Pueblo en Bussang. La obra que dio inicio al Teatro del Pueblo francés fue El Diablo mercader de gotas de Pottecher (cfr. Rolland, 1953).

Romain Rolland promueve en su texto el objetivo de realizar un arte nuevo, destinado al pueblo (lejos de los intereses particulares y de partidismos políticos), y afirma la utilidad del teatro para transformar al público. Dentro de las condiciones morales ${ }^{4}$ que Rolland consideró que debía tener un teatro popular, se encontraba la necesidad de que el teatro funcionara como entretenimiento para los trabajadores: "La primera condición

\footnotetext{
${ }^{4}$ Rolland define moral como “una higiene del espíritu y del corazón” (1953: 84).
} 
de un teatro popular es ser un sedante alivio", es decir, plantea un teatro que sirva para brindar "reposo físico y moral al trabajador" (1953: 82). Así, Romain Rolland afirma que es importante que el público no se aburra en el teatro. De esta forma, podría interpretarse que uno de los deberes del teatro popular sería comportarse como un entretenimiento. Empero, no se puede considerar que el autor francés propuso un divertimento vacuo para el teatro popular, ya que su propósito fue el de mantener cierto equilibrio. Rolland, a su vez, también advirtió que los poetas debían tratar de que sus obras irradien alegría: "Es ser un poco despiadado pretender que, después de su vida triste, se le divierta todavía con el espectáculo de lo triste" (1953: 83). En esta misma línea está la segunda condición propuesta por el teórico francés: "El teatro debe ser una fuente de energía" (Rolland, 1953: 83), entendiendo que el teatro tenía que llevar al público a la acción, y no al estancamiento. Así, expresó:

Que el teatro sea un baño de acción. Que el pueblo encuentre en su poeta un buen camarada de ruta, alerta, jovial, si es necesario, heroico, que pueda apoyarse en su brazo, y cuyo buen humor le haga olvidar las fatigas del camino. El deber de ese compañero está en conducirlo rectamente a la meta, sin que descuide enseñarle, durante el camino, a mirar bien a su alrededor (Rolland, 1953: 83).

La tercera condición fue: "El teatro debe ser una luz para la inteligencia. (...) El pensamiento del obrero se halla ordinariamente en reposo mientras su cuerpo trabaja: es útil que lo ejercite" (Rolland, 1953: 83). En resumen, los tres requisitos que, para Rolland, debía cumplir un teatro que quisiera ser popular eran la alegría, la fuerza y la inteligencia. Estos tenían que ser cumplimentados en su justa medida, ya que presentados en demasía, podían ser contraproducentes:

"El teatro popular deberá evitar dos excesos opuestos, que le son inherentes: la pedagogía moral, que de la obra viva extrae frías lecciones, lo que es a la vez antiestético y torpe (...), y el diletantismo indiferente que a toda costa quiere imponerse y divertir al pueblo (...) Ni buscar la moral ni buscar el placer. Sí, la salud” (Rolland, 1953: 84).

Por lo tanto, Rolland no promovió un teatro predicador -adjetivo que, 
según él, le valía a las lecturas populares del pasado (cfr. 1953)-, aunque sí, le daba al artista un lugar de enseñante.

En relación a un repertorio propicio para ser utilizado en el Teatro del Pueblo, Romain Rolland brindó algunas recomendaciones para los autores que desearan escribir obras. Estas deberían tener:

$1^{\circ}$ Emociones variadas: El público popular acude al teatro para sentir y no para aprender; y como se entrega enteramente a sus emociones, exige que ellas sean variadas; (...) desea reposarse de las lágrimas con la risa, y de la risa con las lágrimas.

$2^{\circ}$ Realismo verosímil (...).

$3^{\circ}$ Moralidad simple: Un público popular necesita, no por ingenuidad sino por salud, hallar en el teatro un apoyo "a la última convicción, que cada uno posee en el fondo de sí mismo, del poder de la victoria definitiva del Bien”, y tiene razón de poseerla, pues es una fuerza necesaria a la vida, es la ley del progreso.

$4^{\circ}$ Probidad comercial: "Porque existe una probidad por parte de los directores y autores en no robar al público, manteniéndolo encerrado durante cuatro horas, para luego darle solamente una hora y tres cuartos de espectáculo" (Rolland, 1953: 94).

A su vez, tuvo una mirada particular sobre la realización de los clásicos en el Teatro del Pueblo. Rolland se manifestó en contra de las palabras grandilocuentes, argumentando que el teatro popular no debía presentar nada que el pueblo no comprendiera y que "a menos de mutilarla, no se puede usar la tragedia del siglo XVIII más que para la lectura, y no para ser representada" (1953: 31). Si bien dijo detestar el hecho de que se tratase a los integrantes del público como si fueran niños (en consonancia con el desdén hacia el teatro predicador que expresó) y admitió que las figuras más grandes del arte dramático (Sófocles, William Shakespeare, Lope de Vega, Calderón de la Barca, Friedrich Schiller) habían sido populares, Rolland consideró que era mejor evitar estos autores en el Teatro del Pueblo: "Ciertamente, admiro a los grandes clásicos y con lo mejor de mi espíritu. Nutrieron casi exclusivamente diez años de mi juventud. A menudo me recojo en ellos, en mis horas de fatiga. iPero qué lejos se hallan de esta vida, de mis ansias, de mis ensueños, de mi diaria lucha!” (1953: 50). 
En especial sobre William Shakespeare, opinó:

Todo nos separa de Shakespeare (...). ¿Sería, pues, necesario desvestir a Shakespeare de la gracia preciosa y salvaje de su estilo? Tarea sacrílega, peligrosa y penosa para quienes lo aman. Y ello tampoco sería suficiente para salvaguardar la integridad de lo que aún quedase. Habríase de cortar, roer, limar en los caracteres y en la acción para ponerlos a tono con el gusto del público popular. (...) Sin duda, el pueblo se halla más cerca que el público actual con ciertas partes de la obra de Shakespeare, de sus instintos y sus actos tumultuosos; pero bien lejos todavía de su profundo pensamiento y sus miles de repliegues. Es miserable querer ajustar un gran hombre a la medida de la multitud (Rolland, 1953: 38).

En vínculo con lo que mencionamos al principio de nuestro trabajo -la identificación de tres líneas en el teatro europeo: teatro independiente / libre, teatro de arte y teatro popular-, podemos advertir que hemos recorrido tres direcciones distintas en el vínculo con los textos elegidos: la cercanía con la realidad, la cercanía con la belleza, y la cercanía con el pueblo. En el primer grupo encontramos piezas de tesis que se proponen dejar un mensaje, asociadas al realismo y al naturalismo. En el segundo grupo hay piezas poéticas, relacionadas con el simbolismo. Y en el tercero, el que estamos exponiendo, lo que se pone en juego es si la pieza representada hará que el público se sienta próximo a ella o no, es decir, se evitan los clásicos por su lejanía temporal, y se recomiendan obras que hagan tanto reír como llorar, y que hagan bien al espectador, lo "sanen". No obstante, corresponde aclarar que estas direcciones no son rígidas. Si bien existieron tendencias dentro de los grupos, muchos de ellos fueron variando su repertorio y llevando a escenas tanto obras clásicas como modernas o de jóvenes dramaturgos.

Asimismo, Romain Rolland observó la necesidad de que el teatro popular fuese accesible para todos, y que su primera cualidad fuera la de constituirse como un espacio de confluencia de todas las clases sociales. También sostuvo que el escenario debería ser lo suficientemente grande como para que entren en él las masas, que -en la medida de lo posible- se suprimiera la maquinaria, y que -preferentemente- se viera bien desde todos los ángulos. Sobre la eliminación de la maquinaria, agregó: 
...creo que la supresión casi total de la maquinaria, habría de ser también una evolución bastante poderosa en otro sentido. Recuerdo las palabras de Michelet: "Un teatro simple y puro, en el que la potencia creadora del corazón, la joven imaginación de poblaciones nuevas, nos eximirán de tantos medios materiales, decoraciones deslumbrantes, etc., sin las cuales los débiles dramaturgos de esta época, no pueden dar un paso más”... El arte ganaría mucho al librarse de ese lujo pueril, del que es su esclavo, y solamente apreciado por los cerebros estragados de los mundanos superficiales inapetentes para experimentar la verdadera emoción del arte. En algunas funciones de la "Obra de los treinta años de Teatro", no fueron empleadas las decoraciones; y simples recitaciones sin decorado ni vestuario, producen, a veces, una impresión cien veces más real, que las representaciones más ostentosas (Rolland, 1953: 86).

En relación a la independencia de los Teatros del Pueblo para con el Estado, Rolland, tomando algunos conceptos de Eugenio Morel y su Proyecto de teatros populares (1900), expresó:

Estos teatros formarían asociaciones entre sí en las que todo sería puesto en común: actores, vestuario y decoraciones, bajo la vigilancia de un comité central y de su delegado, el director general. El Estado solo intervendría para ayudar a reunir los abonos, controlarlos a fin de que se cumplan los principios enunciados por los fundadores del teatro. No se le solicitaría subvención, ni garantía alguna. Los Teatros del Pueblo serían independientes, bajo la égida del Estado (1953: 81).

A su vez, Rolland también sostuvo que el Teatro del Pueblo no era un juego de aficionados.

\section{Palabras finales}

A lo largo de este trabajo hemos sistematizado en tres líneas las distintas corrientes europeas que pueden considerarse antecedentes del teatro independiente porteño. Si bien los grupos que integran cada eje son diversos, $y$ también hay elementos que se pueden encontrar en más de una línea -es decir, las divisiones no son estáticas, sino que se interrelacionan-, creemos 
que la clasificación en tres vertientes ayuda a identificar las cuestiones que aprehendió el Teatro del Pueblo de Buenos Aires. Si bien Barletta tomó el nombre del grupo, y más temáticas, del libro homónimo de Romain Rolland, entendemos que el escritor se sirvió de las tres aristas expuestas para hacer su propio teatro libre, de arte y popular. En este sentido, hemos advertido: "Barletta tomó varios elementos de Rolland para realizar su tarea. Algunos fueron transpolados sin variaciones y otros sufrieron modificaciones. Además, él mismo propuso otras ideas, sirviéndose de muchas teorías, que fueron completamente distintas" (Fukelman, 2015: 154).

La macropoética del Teatro del Pueblo surge del análisis de numerosos artículos, declaraciones colectivas, entrevistas y testimonios (cfr. Barletta, 1931; Barletta, 1961; Dubatti, 2012a; Fos, 2009; López, 1969; Marial, 1955; Ordaz, 1957; Pellettieri, 2006; entre otros). Para finalizar este trabajo, no la volcaremos completa, sino que enunciaremos sintéticamente las partes que consideremos necesarias a los fines explicativos.

En vínculo con la primera línea, Leónidas Barletta declaró independiente a su Teatro del Pueblo, tanto del Estado como de los empresarios teatrales. Así lo expresó en el cuarto artículo de los estatutos del grupo: “El Teatro del Pueblo es independiente y no podrá aceptar subvenciones en dinero efectivo ni ninguna clase de vínculo o negocio con el Estado, empresas comerciales o personas que traben su libre desarrollo o acción" (Larra, 1978: 81)5. De la misma forma, en el artículo quinto, da cuenta de la aberración hacia el teatro comercial:

Considerando que el teatro comercial y negándose a la representación de las obras de aquellos envileciendo en la mayoría de los casos, la mentalidad y el sentimiento del pueblo, al margen de todo ideal, el Teatro del Pueblo reducirá a lo estrictamente indispensable sus relaciones con las organizaciones teatrales, comerciales y gremiales, prohibiéndose el ingreso de los actores y auxiliares del teatro comercial y negándose la representación de las obras de aquellos autores que solo vieron en el teatro una provechosa industria (Larra, 1978: 81).

${ }^{5}$ No obstante, estas palabras, que representan el alma máter del concepto de teatro independiente, no se llevaron, tan estrictamente, de la teoría a la práctica. Por ejemplo, este conjunto pionero aceptó las cuatro salas que el Estado le cedió. 
Este binarismo teatral, por el cual un actor no podía trabajar al mismo tiempo en el teatro comercial y en el independiente, acompañó siempre a Leónidas Barletta. De hecho, llegó a defenestrar cruelmente a artistas del teatro comercial, como fue el caso de, por ejemplo, Alberto Vacarezza. Contra él entabló una peculiar lucha desde su revista Metrópolis.

A su vez, el Teatro del Pueblo representó, en muchas oportunidades, obras de carácter realista, con el propósito de enunciar una tesis y lograr un efecto didáctico en el espectador. La idea de Leónidas Barletta como un "artista ilustrado", lo acerca a varios de los antecedentes europeos, tanto por la pedagogía que pretende realizar desde el arte, como por la creencia de que este tiene una utilidad social. Al respecto, Patricia Fischer y Grisby Ogás Puga afirman: "Barletta sostenía que debían ir a buscar al público, un público 'niño' al que no se le había brindado la posibilidad de la experiencia artística, sino que se lo había embrutecido por la 'mediocridad del teatro corriente" (Fischer y Ogás Puga en Pellettieri, 2006: 198).

Asimismo, en línea con el segundo apartado, este teatro evidenció -desde el segundo artículo de sus estatutos- la pretensión de realizar un arte bello, de alta calidad artística: "Experimentar, fomentar y difundir el buen teatro, clásico y moderno, antiguo y contemporáneo, con preferencia al que se produzca en el país, a fin de devolverle este arte al pueblo en su máxima potencia, purificándolo y renovándolo” (Larra, 1978: 81). En este sentido, llevó a escena a los más grandes representantes del teatro universal, de manera completa, sin cortar ni adaptar sus obras. También se reconoció experimental. A su vez, otorgó una profunda importancia a la figura del director. La estampa de Leónidas Barletta era muy fuerte y era él quien tomaba la mayoría de las decisiones, quedando los actores supeditados a su palabra. En línea con esto, se puede leer el séptimo ítem de su “Decálogo del cómico que se respeta", que indicaba que el actor "Estudiará con lealtad el texto, respetará al autor y se someterá al director, que es el autor del espectáculo, con ejemplar disciplina” (Barletta, 1961: 137). Esta determinación, por otra parte, también se expresa en el reglamento de la institución, cuyo artículo 2 manifiesta: "La voluntad de todos se delega en el Director, a

${ }^{6}$ Dubatti llama "artista ilustrado" al "creador teatral que considera que su trabajo lo acerca al conocimiento de la verdad, lo hace puro en su ética y le permite saber más que el espectador, al que debe mostrarle el camino correcto" (2012b: 83). 
quien se le ratifica confianza periódicamente, de manera que en la presente reglamentación, cuando se dice Dirección se entiende por la voluntad de todos" (Larra, 1978: 83).

Por último, en relación con la línea del teatro popular, el Teatro del Pueblo ofreció precios económicos, también estipulados desde sus estatutos, esta vez, el artículo $3^{\mathrm{o}}$ : "Con el objeto de hacer accesible este arte a todas las clases sociales, las representaciones serán (...) gratuitas o a bajo precio, siendo el normal y corriente de veinte centavos y en ningún caso podrá exceder de un peso" (Larra, 1978: 82). Igualmente ejecutó funciones gratuitas, tanto en espacios públicos como en colegios. Para esto, el grupo de Barletta contó con un "Carro de Tespis", un vehículo (carro-escenario), pintado por el escenógrafo español Fontanals, en el que el elenco recorría distintas zonas ofreciendo sus funciones $\mathrm{y}$, muchas veces, también conferencias. A lo largo de sus años de trabajo, el conjunto visitó -además de plazas, cafés, clubes y escuelas de la ciudad de Buenos Aires- la ciudad uruguaya de Montevideo, numerosas provincias argentinas, y muchos pueblos de la Provincia de Buenos Aires. Asimismo, al igual que Rolland, Barletta consideraba que los artistas del Teatro del Pueblo no eran aficionados, pero -a diferencia de él-, se distanciaba de la visión del teatro como entretenimiento.

Gracias a los aportes de estos pensadores y hacedores de teatro de Europa -y de Argentina-, Barletta se nutrió de material para dar el puntapié inicial para el gran movimiento que fue el teatro independiente en sus primeros años. A su vez, los elementos que fue tomando, más otros nuevos, se entremezclaron para conformar una práctica con características propias, que resultó novedosa en Buenos Aires, y que luego se fue expandiendo dentro de la ciudad, por las distintas provincias del país y por algunas zonas de Latinoamérica. Asimismo, otros grupos que lo continuaron se sirvieron del recorrido hecho por su teatro, pero también combinaron nuevos elementos $^{7}$, contribuyendo a conformar el enraizado complejo y rico en su diversidad que es el teatro independiente argentino ${ }^{8}$.

Algunos de estos elementos también fueron tomados de las experiencias europeas, por ejemplo en 1932 surge el Teatro Proletario, utilizando el homónimo del teatro creado por Piscator. Asimismo, la experiencia de la escuela de formación de arte dramático que propuso Copeau no fue seguida por Barletta, pero diversos grupos, encabezados por La Máscara, la continuaron.

${ }^{8}$ Queda para un próximo trabajo el abordaje completo hacia la archipoética o poética abstracta del teatro independiente en Buenos Aires. 


\section{Referencias}

Barletta, L. (1931). Consideraciones sobre el Teatro del Pueblo. Metrópolis $1, \mathrm{~s} / \mathrm{p}$.

(1961). Manual del actor. Buenos Aires: Ediciones del Teatro del Pueblo.

De Rivas Cherif, C. (2013). Cómo hacer teatro: apuntes de orientación profesional en las artes y oficios del teatro español. Valencia: Pre-Textos.

De Rivas, E. (2013). Introducción. En C. de Rivas Cherif, Cómo hacer teatro: apuntes de orientación profesional en las artes y oficios del teatro español (pp. 9-20). Valencia: Pre-Textos.

Dubatti, J. (2012a). Introducción a los estudios teatrales. Propedéutica. Buenos Aires: Atuel.

. (2012b). Cien años de teatro argentino: del Centenario a nuestros días. Buenos Aires: Biblos.

Fischer, P. V., Ogás Puga, G. (2006). El Teatro del Pueblo: período de culturalización (1930-1949). En O. Pellettieri (ed.), Teatro del Pueblo: una utopía concretada (pp. 159-212). Buenos Aires: Galerna.

Fos, C. (2009). Leónidas Barletta: el actor en el mundo del Hombre de la Campana. En J. Dubatti (coord.), Historia del actor II. Del ritual dionisíaco a Tadeusz Kantor (pp. 307-324). Buenos Aires: Colihue.

Fukelman, M. (2015). El vínculo entre Romain Rolland y Leónidas Barletta para el surgimiento del teatro independiente. AdVersuS. Revista de Semiótica, 29, 134-155.

Lalou, R. (1962). Medio siglo de teatro francés. Buenos Aires: Compañía General Fabril Editora.

Larra, R. (1978). Leónidas Barletta. El hombre de la campana. Buenos Aires: Conducta.

López, J. A. (1969). Reportaje al actor Elías Wacks por José Ariel López. Conducta, $15, \mathrm{~s} / \mathrm{p}$.

Marial, J. (1955). El teatro independiente. Buenos Aires: Alpe.

Monner Sanz, J. M. (1958). Introducción al teatro del siglo XX. Buenos Aires: Columba.

Ordaz, L. (1957). El teatro en el Río de La Plata - Desde sus orígenes hasta nuestros días. Buenos Aires: Ediciones Leviatán. 
. (1992). Leónidas Barletta: hombre de teatro. Disponible en http:// www.teatrodelpueblo.org.ar/dramaturgia/ordazoo3.htm.

Paul, C. (2013). Realizarán jornada de reflexión alrededor de la obra de Konstantin Stanislavski. La Jornada, 3.

Pellettieri, O. (ed.). (2006). Teatro del Pueblo: una utopía concretada. Buenos Aires: Galerna.

Piscator, E. (1979). El teatro como profesión de fe. En B. Brecht, G. Grosz y E. Piscator, Arte y sociedad (pp.39-51). Buenos Aires: Ediciones Caldén.

Rolland, R. (1953). El Teatro del Pueblo. Ensayo de Estética de un Teatro Nuevo. Buenos Aires: Quetzal.

Shaw, G. B. (1895). S/t. The Saturday Review, XXIX, 126. 